\title{
A CONTABILIDADE COMO CIÊNCIA SOCIAL E SUA \\ CONTRIBUIÇÃO PARA O CAPITALISMO
}

\section{ACCOUNTING AS SOCIAL SCIENCE AND ITS CONTRIBUTION TO CAPITALISM}

Data do recebimento do artigo: 18/05/2014

Data do aceite do artigo: 23/9/2014

Data da publicação: 8/12/2014

Processo de Avaliação: Double Blind Review

\author{
Gleubert Carlos Coliath ${ }^{1}$ \\ Doutor em Ciências Sociais \\ Mestre e Graduado em Ciências Contábeis \\ Professor da Pontifícia Universidade Católica de São Paulo
}

\section{RESUMO}

Este artigo tem como objetivo principal demonstrar que a Contabilidade pode ser observada e classificada como uma Ciência Social, onde as suas relações e práticas sociais são necessárias para interpretação, uso e aplicação na sociedade como instrumento de prestação de contas. Como objetivo específico o artigo demonstra a importância e contribuição da Contabilidade no desenvolvimento da sociedade capitalista.

Palavras-chave: Capitalismo. Ciências Sociais. Contabilidade.

\begin{abstract}
This article's main objective is to demonstrate that accounting can be observed and classified as asocial science, where it's social relationships and practices are necessary for interpretation, use and application in society as an instrument of accountability. Specific objectives the article demonstrates the importance and contribution of Accounting in the development of the capitalist economy.
\end{abstract}

Keywords: Capitalism. Social Sciences. Accounting.

\footnotetext{
${ }^{1}$ Autor para correspondência: Pontifícia Universidade Católica de São Paulo - R. Monte Alegre, 984 Perdizes, São Paulo - SP,Brasil - 05014-901
} 


\section{A CONTABILIDADE E AS CIÊNCIAS SOCIAIS}

Diversas são as tentativas de definir o conceito de Ciência, mas todas apontam na indicação de algumas considerações indispensáveis para o seu entendimento e assimilação.

Megale (1990, p.41) conceitua Ciência como "o conjunto de conhecimentos obtidos através da investigação sistemática, objetiva e empírica".

Muniz et al (2005) observam que, de certa forma, algum elemento importante do conceito de Ciência encontra-se quase sempre presente em qualquer esclarecimento ou explicação, como certeza, previsão e lei, sendo que uma grande parte das pessoas possui, mesmo que elementar e precária certa noção de Ciência.

Compreende-se então que Ciência é o conjunto de diversos conhecimentos vinculados entre si, formando uma base teórica que constantemente está sendo posta à prova, que foi gerada por um processo de investigação criteriosa, metódica, por estudo, pesquisa e busca de dados, dentro de uma lógica ou coerência, visando alcançar a verdade e retratar fidedignamente o objeto ou fenômeno observado, de forma imparcial, sem a opinião pessoal do pesquisador, indicando que o conhecimento é resultado de experiência que garante, com clareza e objetividade, os seus resultados alcançados. Megale (1990, p. 42).

Iudícibus (2002, p.68) considera que "há inúmeras classificações de Ciências e elas se dividem em dois grupos: Formais e Exatas; Factuais (que se desdobram em Naturais e Sociais)"

Megale (1990, p. 53) explica que as Ciências Exatas são abstratas, algumas não necessitam de confirmação empírica como Matemática, Geometria e Astronomia. As Ciências Naturais têm como objeto de estudo as coisas concretas, os seres vivos, como Geografia, Botânica, Biologia, Química e Física. As Ciências Humanas e Sociais investigam as relações sociais, estuda o homem não como ser vivo, mas como ser social, criador de cultura, em quaisquer que sejam os aspectos da vida social, como Antropologia, Direito, Economia, Psicologia Social e Sociologia.

Entre as diversas classificações de Ciência, observa-se a Contabilidade como uma das mais antigas e para alguns pesquisadores da história contábil, surgiu há aproximadamente 4.000 a.C. com comprovados achados arqueológicos.

A Contabilidade, no início em sua forma rudimentar, existe desde o princípio da civilização, porém nota-se um desenvolvimento lento ao longo dos séculos. Somente por volta do século XV é que ela alcançou um patamar de desenvolvimento com a descoberta da obra ${ }^{2}$ do Frei Luca Pacioli dando início ao período científico da

\footnotetext{
${ }^{2}$ Descrito pela primeira vez em 1494, na Itália, pelo frade Luca Pacioli no livro "Summa de Arithmetica, Geometria, Proportioni et Proportionalità" (Coleção de conhecimentos de Aritmética, Geometria, Proporção e Proporcionalidade), no capítulo "Particulario de computies et Scripturis" (Contabilidade por Partidas Dobradas)
} 
Contabilidade, com a introdução do método das partidas dobradas ${ }^{3}$ ou partidas duplas como uma metodologia de registro, utilizada até a atualidade.

A criação desse método foi uma resposta fornecida pela Contabilidade aos novos e complexos problemas enfrentados pelos homens de negócio da época. Ao contrário do que se pode deduzir à primeira vista, esse método, não importa em repetição de registro. Neste caso, a palavra partida, na técnica contábil, tem a conotação de lançamento ou assentamento escrito (Muniz et al, 2005).

Campiglia (1966) considera que o processo de escrituração das partidas dobradas é elaborado por meio de sistemas de contas próprias onde são registrados componentes específicos, as variações positivas e negativas que modificam os valores absolutos dos elementos reais e também, os seus efeitos sobre os elementos derivados.

Crepaldi (1999) esclarece o princípio fundamental e a regra geral de escrituração por partidas dobradas: "Todo crédito que é lançado numa conta faz surgir outra ou outras contas em que é registrada a mesma importância a débito", sendo o principal cuidado a ser observado nesse método é determinar quem é devedor e quem é credor.

A característica fundamental desta metodologia é evidenciada na sua demonstração matemática. Sendo o patrimônio uma equação, a igualdade dos seus dois elementos será constante, desta forma, Ativo $=$ Passivo, débito $=$ crédito . Logo, um fato administrativo deve resultar sempre em duas variações equivalentes (Campiglia, 1966).

Um aumento ou redução de um dos elementos do Ativo (bens e direitos), deve corresponder necessariamente a um aumento ou redução equivalente em outro elemento do mesmo termo, ou ainda, em componentes do Passivo (dívidas e obrigações).

Em virtude da equação patrimonial da contabilidade possuir uma relação direta com a matemática, a Contabilidade por muitas vezes é confundida com uma Ciência Exata, porém a matemática é utilizada apenas como uma ferramenta quantitativa para mensuração de valores, com o objetivo de explicar e esclarecer os fenômenos que afetam o patrimônio de uma entidade.

O ambiente contábil tardou um certo lapso de tempo para adaptar-se a nova realidade. Depois da segunda guerra mundial, devida a demanda econômica, surgiu uma grande necessidade de desenvolver especialidades em todas as Ciências Sociais, com o objetivo de reconstruir os países afetados pela guerra (Muniz et al, 2005).

Barbi e Palotta (2002, p.74) afirmam que "surgem os técnicos especialistas no momento em que na sociologia ocorre uma fragmentação com o surgimento das Sociologias Aplicadas".

Dessa forma, a contabilidade está ligada à Sociologia no que se refere à análise e interpretação dos fenômenos sociais estudados na Sociologia das Organizações, e assim, conclui-se que a Contabilidade está inserida no contexto da Sociedade Capitalista, objeto de estudo da Sociologia Geral.

\footnotetext{
3 Partidas Dobradas: metodologia de escrituração contábil onde são utilizadas duas partidas, uma chamada de débito e outra de crédito, também conhecia como partidas duplas.
} 
Para estas pesquisadoras, a Contabilidade como Ciência é interlocutora da Sociologia, de maneira que, em conjunto com a Economia, sistematizam dados, não só das organizações formais, mas também das ações humanas.

A profissão contábil não deve se limitar apenas a cumprir somente requisitos fiscais e burocráticos, mas contribuir no ambiente de gestão, pois o Contador, em função de sua interação com o sistema da empresa, possui informações relevantes para a tomada de decisões.

Baseado nesta análise, Megale (1990) considera que é possível identificar a Contabilidade como uma Ciência Social, embora o senso comum, em geral, tem uma tendência de identificá-la como sendo uma Ciência Exata. Para este autor, a contabilidade é classificada como Ciência Social Aplicada, subgrupo das Ciências Humanas e Sociais, estando, assim, entre as Ciências Sociais mais jovens.

Em sua pesquisa, Kelm (2004, p.124) aponta algumas características do relacionamento das Ciências Sociais com a Contabilidade.

A primeira característica da Ciência Contábil é aquela que envolve o caráter eminentemente histórico das Ciências Sociais. Assim como a estática patrimonial - não obstante constituir-se em um recorte histórico delimitado - reflete uma trajetória da entidade e das ações de seus dirigentes, a Ciência Social é sempre analisada a partir de uma configuração espacial e histórica específica.

A segunda característica a ser evidenciada é o fato que não é somente o investigador que fornece sentido a seu trabalho intelectual, mas os seres humanos, os grupos e as sociedades é que dão significado e intencionalidade as suas ações e construções, na medida em que as estruturas sociais nada mais são que ações objetivadas, ou seja, o nível de consciência histórica das Ciências Sociais está referenciado ao nível de consciência histórica social.

Minayo apud Kelm (2004, p.124), observa que a investigação social "é sempre tateante, em que o presente é marcado pelo passado e projetado para o futuro, num embate constante entre o que está dado e o que está sendo construído".

A terceira característica é que nas Ciências Sociais existe uma identidade entre o sujeito e o objeto. Nessa área, a pesquisa trabalha com seres humanos que, por razões culturais, de classe, faixa etária, ou por qualquer outro motivo, têm um substrato comum de identidade com o pesquisador, tornando-os solidariamente comprometidos.

Uma quarta característica das Ciências Sociais é o seu caráter ideológico, não isento das observações, percepções e valores dos sujeitos ou pesquisador. $\mathrm{Na}$ contabilidade essa característica pode ser observada na análise e avaliação de organizações, ou nos processos de avaliação de intangíveis, como exemplo um caso da investigação do impacto do valor de uma marca na projeção do fluxo de caixa futuro de uma entidade, que inclui uma série de considerações e percepções do avaliador.

Esta condição preditiva da Contabilidade é destacada por Franco (1997, p. 58) quando afirma que: 
Nisso está o fundamento científico da Contabilidade - na possibilidade de previsão dos efeitos gerados por determinados fenômenos patrimoniais. A análise, a comparação e a interpretação desses efeitos dão-lhe capacidade de previsão e, consequentemente, fundamento científico inquestionável.

A contabilidade poderá utilizar de um conjunto de métodos e técnicas auferíveis e mensuráveis, sempre que o processo de verificação análise for prospectivo, e será exigido o uso de expectativas com relação ao ambiente e do próprio relacionamento da célula social com a sociedade, onde as interpretações e opiniões poderão divergir entre profissionais ou em relação a percepções de possíveis modificações do contexto.

Da mesma forma que a Resolução do Conselho Federal de Contabilidade $\mathrm{N}^{\circ}$. 750/93 pronuncia o princípio da prudência, cujo objetivo é limitar a ação diante de alternativas e possibilidades incertas, as percepções do contador com relação às repercussões de decisões sobre o desempenho futuro da célula social são tais que poderiam, em certas condições, divergir sobre um parecer ou diagnóstico de sucesso ou não, de uma alternativa de investimento, sem que isto demonstre falta de capacidade técnica de um ou outro profissional.

Mediante estes fatos Franco (1997, p.61) esclarece que:

Quanto às Ciências Sociais, entre as quais as Ciências Econômicas (das quais a Contabilidade faz parte), elas dependem do comportamento do ser humano, imprevisível, em face de seu livre-arbítrio. Daí a dificuldade de certas previsões, pois estas estarão sempre condicionadas à conduta humana.

A ação produzida pela contabilidade, embora envolva um conjunto de técnicas e procedimentos comumente retratado de modo quantitativo, tem em sua verdadeira essência um grande apelo qualitativo.

Exemplo disso pode ser observado na pesquisa de Fragoso e Ribeiro Filho (2004) onde apresentaram um estudo cujo objetivo consistiu em avaliar se doutores em Contabilidade no Brasil, que apresentam um currículo interdisciplinar, ou seja, que possuem formação não somente em Contabilidade, mas também em outras áreas de conhecimento como Economia, Administração, Sociologia etc., onde estes vivenciam com mais intensidade o processo de pesquisa que os doutores formados somente em Contabilidade (graduação, mestrado e doutorado).

Os dados da pesquisa, referentes à produção científica dos doutores, foram extraídos dos Currículos Lattes do Conselho Nacional de Desenvolvimento Científico e Tecnológico (CNPq).

Com base na análise dos dados, utilizando-se testes estatísticos como o Wilcoxon, os pesquisadores concluíram que o aspecto interdisciplinar não proporcionou vantagens ou superioridade na produção científica das amostras analisadas.

Embora a pesquisa realizada (Op. cit., p.104) verificou-se que: 
A amostra com perfil interdisciplinar foi mais consistente e atuante no processo de pesquisa (produção científica) ao longo do tempo, e isto valida a questão de que "as inquietações", que geram os problemas de pesquisa, também são constantes.

Também foi observado nesta pesquisa que o perfil de formação em outras áreas de conhecimento contribui, como vantagem, para que estes acadêmicos tenham uma visão mais ampla e adaptada em relação a realidade social que os cercam.

Assim, Minayo (2000, p. 15) considera que a realidade social retrata-se no próprio dinamismo da vida individual e coletiva com toda a riqueza de significados dela transbordante. Essa realidade é mais rica que qualquer teoria, qualquer pensamento ou qualquer discurso que se possa elaborar sobre ela.

A princípio, observa-se certa incapacidade de incorporação da complexidade da vida social em modelos científicos plenos, porém isso não significa que o complexo não seja, ou não possa ser devidamente incorporado à dinâmica de ação da contabilidade.

As Ciências Sociais possuem argumentos, instrumentos e teorias capazes de se aproximar da grandiosidade que é a vida dos seres humanos em sociedades, ainda que de forma incompleta ou imperfeita. Deste modo, ela aborda o conjunto de expressões humanas presentes nas estruturas, nos processos, nos sujeitos, nos significados e nas representações, onde a contabilidade se encaixa perfeitamente neste ambiente.

\section{A CONTABILIDADE E O CAPITALISMO}

A contabilidade surgiu da necessidade do ser humano em obter informações sobre o controle das suas riquezas. É o homem que interage e modifica o seu patrimônio, utilizando práticas de controles e registros que possibilitam o entendimento e a interpretação da evolução das suas riquezas.

Considerada como uma ferramenta indispensável para controle econômico, a contabilidade desponta como uma área de conhecimento de caráter utilitário para o desenvolvimento da sociedade.

Iudícibus (1997, p.44) afirma que:

A Contabilidade é uma ciência essencialmente utilitária, no sentido de que responde, por mecanismos próprios, a estímulos dos vários setores da economia. Portanto, entender a evolução das sociedades, em seus aspectos econômicos, dos usuários da informação contábil, em suas necessidades informativas, é a melhor forma de entender e definir os objetivos da Contabilidade.

Entende-se que para compreender os objetivos da contabilidade é necessário observar a evolução econômica das sociedades e as suas necessidades quanto à informação.

Lopes de Sá (1997, p.15) ensina que a contabilidade surge com a própria civilização, sendo: 
A Contabilidade nasceu com a civilização e jamais deixará de existir em decorrência dela; talvez, por isso, seus progressos quase sempre tenham coincidido com aqueles que caracterizaram os da própria evolução do ser humano.

O surgimento do sistema econômico sob o regime capitalista exigiu da sociedade a busca por prestação de contas e consequentemente a demanda por informações contábeis adequadas a uma nova necessidade.

Riahi-Belkaoui apud Pinheiro e Nakagawa (2004) afirma que a contabilidade tem sido ligada ao capitalismo por alguns historiadores da Economia sob o argumento de que o processo de escrituração contábil por meio das partidas dobradas tem sido vital ao desenvolvimento e evolução do capitalismo.

Weber (2002, p.7) observa esta argumentação ao declarar:

A moderna organização racional das empresas capitalistas não teria sido possível sem dois outros fatores importantes em seu desenvolvimento: a separação dos negócios da moradia da família, fato que domina completamente a vida econômica e, estritamente ligada a isso, uma contabilidade racional.

O termo contabilidade racional citado por Weber entre 1904 e 1905 lança a hipótese de que esta observação pode estar ligada ao amadurecimento de conceitos e metodologias contábeis utilizadas na época.

A questão da separação dos negócios da moradia da família nada mais é do que um princípio fundamental de contabilidade chamado atualmente de princípio da entidade, onde pressupõe que os negócios devem ser tratados separadamente da vida pessoal dos proprietários.

A racionalidade da contabilidade comentada por Weber, como hipótese, pode ser considerada uma pista evidente da consolidação do método das partidas dobradas como um instrumento ou mecanismo contábil essencial para solucionar os diversos problemas que surgiram em um período Pós-Revolução Industrial.

Com a consolidação da economia sob o regime capitalista, o conhecimento e a interpretação do desempenho econômico de uma organização empresarial seria a grande questão a ser respondida pela contabilidade.

O desempenho econômico está diretamente relacionado com os resultados alcançados pela organização empresarial, no caso positivo o lucro ou no caso negativo o prejuízo.

Ijiri (1975) ao comentar a relação entre a Contabilidade e o Capitalismo afirma que o capitalismo sem a mensuração do lucro é tão inconcebível como seriam os jogos Olímpicos sem os registros dos resultados dos esportes.

O conceito de lucro é primordial para o detentor do capital, não sendo algo simples de definir em uma atividade empresarial, principalmente diante da complexidade de um ambiente industrial, que exige controle rigoroso sobre os fatores 
produtivos para identificação dos custos de fabricação. Não há como determinar o lucro sem conhecer os gastos gerais de fabricação por unidade produzida.

A contabilidade necessita de critérios para determinar modelos de apropriação e distribuição dos gastos de produção, levando em consideração as características produtivas, como por exemplo, produção por encomenda ou produção em série.

O lucro para o capitalista é o produto do seu investimento, fruto do esforço econômico e financeiro dispendido, onde são colhidos os dividendos 4 que remuneram o capital investido.

Marx (1865, p.40) ao descrever as diversas partes em que se divide a mais-valia, conceitua como lucro a parcela não remunerada do trabalho incluída no valor total da mercadoria, onde esclarece: "a mais-valia, ou seja, àquela parte do valor total da mercadoria em que se incorpora o sobretrabalho, ou trabalho não remunerado, eu chamo lucro".

Como o lucro está intimamente ligado ao capitalismo pela sua concepção, a contabilidade tem como missão contribuir para solucionar este problema de mensuração na busca de atribuir e determinar o seu valor, assim como, o contador na tomada de decisão tem em seu escopo garantir a finalidade principal das empresas que é o lucro, dessa forma, deve-se tomar decisões em busca da maximização dos lucros.

Gorender e Singer ao prefaciar a obra designada O Capital: Crítica da Economia Política in Marx (1996, p.40) citam que "[...] a produção industrial moderna, sejam os países capitalistas ou socialistas, é tecnicamente impraticável sem contabilidade".

Sombart apud Pinheiro e Nakagawa (2004, p.4) afirma que "não se pode imaginar o que seria do capitalismo sem a escrituração contábil pelo método das partidas dobradas: os dois fenômenos estão conectados tão intimamente como estão a forma e o conteúdo".

\section{CONSIDERAÇÕES FINAIS}

A contabilidade como prática ou ciência não deve ter como objetivo fragmentar o conhecimento a uma condição que somente poucos estudiosos possam compreendê-la.

Este conhecimento deve ser cada vez mais facilitado e colocado à disposição da sociedade e dos agentes que necessitam das informações que possibilitem a compreensão das modificações do patrimônio e as relações sociais que este pode influenciar.

Muito se tem feito na busca de normas e princípios que atendam a esta necessidade de interpretação do fluxo de capital investido nas atividades empresariais e sociais.

O conceito de contabilidade atualmente pode ser considerado como a linguagem dos negócios, e cabe aos profissionais conhecedores e criadores das práticas estabelecidas uma posição de mediadores entre os acionistas ou quotistas proprietários e os interesses sociais nos quais a contabilidade se propõe a contribuir com as suas leituras e interpretações.

${ }^{4}$ Dividendos é a parcela do lucro empresarial destinada ao proprietário, dono, sócio ou acionista. 
A contabilidade analisada e observada pela ótica das Ciências Sociais, facilita o processo de compreensão a ser estabelecido entre os grupos de interesse que dependem de informações confiáveis e mensuradas de acordo com métodos e práticas que possam ser interpretados, absorvidos e consumidos com a devida segurança proposta por suas demandas de trabalho e investigação científica.

Como uma Ciência Social, a contabilidade tem o papel fundamental de servir como um instrumento de medição e mediação, capaz de interagir não somente sob o aspecto quantitativo, mas interagir também abordando o aspecto qualitativo das relações humanas e sociais que são afetadas diretamente pela prestação de contas nos mais diversos setores da sociedade.

O ambiente capitalista, como sistema econômico, não foi o responsável pelo surgimento da contabilidade. Este conhecimento já existia muito antes deste sistema ter dados os seus primeiros passos rumo a sua consolidação, e a sua prática, considerando as limitações da sua época, já havia sido estabelecida, mesmo que de forma rudimentar, pelos povos da antiguidade.

Este ambiente possibilitou inúmeros desafios para a contabilidade no sentido de buscar novas soluções e procedimentos técnicos que pudessem contribuir para a interpretação do alto fluxo de capital investido sob uma nova forma de organização social, onde a rentabilidade representada pelo lucro era o foco principal da atenção dos detentores do capital.

O sistema capitalista teve uma grande contribuição da contabilidade e suas práticas, porém a existência de um não depende do outro. Os negócios gerados pelo capitalismo precisam de controle, registro e interpretação, e a contabilidade possui estes recursos. Tal condição é uma necessidade inerente ao processo de evolução da sociedade.

\section{REFERÊNCIAS}

BARBI, Regiane de Cássia; PALOTTA, Valenilza de Fátima. As raízes históricas da contabilidade sob uma abordagem social: uma discussão sobre os reais objetivos do balanço social. LaSalle - Revista de Educação, Ciencia e Cultura, Canoas, v. 7,n.2, p. 71-83, 2002.

BRASIL. Conselho Federal de Contabilidade. Resolução n.750, de 1993. Brasília, DF.

CAMPIGLIA, Américo Oswaldo. O método das partidas dobradas. São Paulo: Editora da Universidade de São Paulo, 1966.

CREPALDI, Silvio Aparecido. Conceitos, objetivos, finalidades, técnicas contábeis e campo de aplicação da Contabilidade. 2.ed. São Paulo: Atlas, 1999.

FRAGOSO, Adriana Rodrigues; RIBEIRO FILHO, José Francisco. Um Estudo Aplicado sobre o Impacto da Interdisciplinaridade no Processo de Pesquisa dos Doutores em Contabilidade no Brasil. Artigo apresentado no IV Colóquio Internacional sobre Gestão Universitária na América do Sul, Florianópolis - Brasil, dez. 2004.

FRANCO, Hilário. Paradigmas da teoria contábil. Revista Brasileira de Contabilidade. Brasília, n. 5, p. 52-63, jun./1997. 
IJIRI, Yuji. Theory of Accounting Measurement.Trad.de Gleubert C. Coliath. New York: American Accounting Association, 1975.

IUDÍCIBUS, Sérgio de. Conhecimento, Ciência, Metodologias Científicas e Contabilidade. Revista Brasileira de Contabilidade, Brasil, ano 31, n. 134, p. 68-71, mar./abr. 2002.

Teoria da Contabilidade. 5.ed. São Paulo: Atlas, 1997.

KELM, Martinho Luís. Conhecimento Contábil no Contexto das Ciências Sociais e a Investigação Científica. Desenvolvimento em Questão. Unijuí. Ano 2. n.3. Jan./Jun. 2004. Disponível em:<http://www.unijui.edu.br $>$. Acesso em: 12 set. 2012.

LOPES DE SÁ, Antonio. História Geral e das Doutrinas da Contabilidade. São Paulo: Atlas, 1997.

MARX, Karl. O Capital: Crítica da Economia Política. Vol.I. São Paulo: Nova Cultural, 1996.

. Salário, Preço e Lucro. Publicações LCC Eletrônicas, 1865. Disponível em: $<$ http://www.culturabrasil.pro.br $>$. Acesso em: 12 set. 2012.

MEGALE, Januário Francisco. Classificação das Ciências. 2. ed. São Paulo: Atlas, 1990.

MINAYO, Maria Cecilia de Souza (Org.). Pesquisa social: teoria, método e criatividade. 17.ed. Petrópolis: Vozes, 2000.

MUNIZ, Anderson A. Ferreira. et al. Contabilidade - Ciências Exata ou Ciência Social Aplicada?: O relacionamento da Contabilidade com a Matemática, com o Direito e com as Ciências Sociais. Pontifícia Universidade Católica de Minas Gerais. Belo Horizonte, 2005. Disponível em:<http://sinescontabil.com.br >. Acesso em: 12 set. 2012.

PINHEIRO, Paulo Bekmessian; NAKAGAWA, Masayuki. Origem Genética da Contabilidade. $1^{\circ}$. Congresso USP Iniciação Científica em Contabilidade. São Paulo, Outubro 2004. Disponível em: $\langle$ http://www.congressousp.fipecafi.org $>$. Acesso em: 12 set. 2012.

WEBER, Max. A Ética Protestante e o Espírito do Capitalismo. 2. ed. rev. São Paulo:Pioneira - Thomson Learnig, 2002. Disponível em: $\underline{\text { http://www.praxis.ufsc.br. }}$ Acesso em: 12 set. 2012. 